\title{
Engaged In Research/Achieving Balance: A Case Example Of Teaching Research To Masters Of Social Work Students
}

\author{
Christine A. Walsh, University of Calgary, Canada \\ Patsy J. Casselman, University of Calgary, Canada \\ Jamie Hickey, University of Calgary, Canada \\ Noelle Lee, University of Calgary, Canada \\ Harold Pliszka, University of Calgary, Canada
}

\begin{abstract}
This article considers the use of participatory action research and Photovoice as a tool for engaging graduate level social work students in research education. Photovoice is an investigative tool that assists people in critically reflecting on the everyday social and political realities of their lives, enriching their understanding of their communities and the issues pertinent to them, while at the same time, giving them a voice from which to educate others on these issues. In the context of a group assignment, 26 social work students, enrolled in an introductory graduate research course, were asked to reflect upon the question, "What does balance look like for you in the MSW program?" Thirty-two photographs with captions were submitted and analyzed by class members for relevant themes. Balance was described as existing along a continuum from balanced to unbalanced and was comprised of four major themes: connection, nurturance, keeping perspective, and disengagement. Although this teaching strategy was not formally assessed, preliminary impressions are that students benefited from participating in the Photovoice activity.
\end{abstract}

Keywords: Photovoice; Participatory Action Research; Research; Social Work

\section{INTRODUCTION}

(E) ocial work educators are tasked with creating curricular content to facilitate knowledge acquisition and skill development in research among social work students (Lyons, 2000). Social work research education has, however, been the focus of considerable debate and it has been characterized as marginalized within curriculum. Several factors have led to the marginalization of research teaching in social work including a lack of time, staff skill and resources (MacIntyre \& Paul, 2013). Further, MacIntyre and Paul (2013) suggest that lack of centrality of research in social work pedagogy arises as a consequence of the "reservations and resistance on the part of educators, students and practitioners towards engaging with research" and is predicated on the "fundamental debate about the nature of the social work discipline, and the relationship between research and practice" (p. 685).

The emphasis on evidence-based practice, that is, the use of empirical evidence to determine best practice that is most beneficial for those being helped (Gambrill, 2006), has been identified as important in social work and other helping professions (Howard, Himle, Jenson, \& Vaughn, 2009; Jenson, 2007; Maynard, 2007; Nevo \& Slonim-Nevo, 2011; Thyer, 2008). Evidence-informed practice, which takes into account the best available research evidence, practitioner wisdom, and user views is also gaining momentum (Epstein, 2011; Nevo \& Slonim-Nevo, 2011), as it is believed to be more all-encompassing in addressing the complexities within the field and the variety of factors that impinge on the decision-making process (Petch, 2010). Evidence-based and evidence-informed practice, which it is argued, lead to optimal service provision, are best achieved through social work research (Cameron \& Este, 2008). Social work research education is vital in achieving this goal. 
The Canadian Association of Schools of Social Work (CASSW, 2004) asserts the primacy of research education, recommending that Master of Social Work (MSW) students should be able to "combine analytic ability, professional judgment, specialized or advanced intervention and research competence" (p. 19).

Despite the compelling arguments for research skills, historically social work students have been described as research-reluctant (Epstein, 1987) and research has been described as "the most dreaded course in the curriculum" (Jacobson \& Goheen, 2006, p. 87). Students' emotional, cognitive or behavioral responses to research, particularly during the initial learning stages, have included fear, anxiety, self-doubt, confusion, procrastination and taskaversion (Maschi et al., 2007; Maschi, Probst, \& Bradley, 2009). However, not all students have misgivings about research; some studies have found students to have a positive view of research (Lazar, 1991 as cited in Holley et al., 2007; Harder, 2010) and differing attitudes and diverse preconceived notions about research (Secret, Ford, \& Rompbf, 2003), along with varying levels of research knowledge and skill.

Among a plethora of techniques, experiential and active teaching methods have been advanced to facilitate student engagement and facilitate student learning (Barraket, 2005; Johnson, 2010, Tetloff, Hitchock, Battista, \& Lowry, 2014). This paper presents a case example of a participatory, active learning strategy to teach research for graduate level social work students.

\section{LITERATURE REVIEW}

Social work educators are tasked with finding effective ways of engaging students in research education. Various models, approaches and teaching strategies have been utilized (Epstein, 1987; Harder, 2010; Hewson, Walsh, \& Bradshaw, 2010; Jacobson \& Goheen, 2006; Maschi, Probst, \& Bradley, 2009; Walsh \& Hewson, 2012). Employing a variety of formats of lecture, critical thinking exercises, and experiential activities, educators are better able to attend to the diversity of learning styles of students (Holley, Risley-Curtis, Stott, Jackson, \& Nelson, 2007; Lundahl, 2008). Jacobson and Goheen (2006) argue that experiential approaches are effective in facilitating student empowerment. These approaches include: service learning; community-based or agency-based research; integrating research into practice courses; applying cognitive-behavioral and social learning theories to learning research; cooperative learning; and group research projects facilitated by faculty volunteers. Educators are also encouraged to "focus their courses on the practical rather than the theoretical, and to replace the traditional deductive emphasis of research teaching with more inductive experiential approaches to student learning" (Green, Bretzin, Leininger, \& Stauffer, 2001, p. 333). As an example, Carawan et al., (2011) used creative arts (drawing, body sculpture, sculpting with clay, photography, collage making, storytelling, haiku writing, and baking) to enhance student engagement and learning in a qualitative research course. They suggested that creating a safe, learner-centered environment that invited active engagement, situating cognition in the research process combined with critical reflection were necessary pre-conditions for optimum learning.

Active learning strategies are predicated on students becoming engaged participants in the learning process rather than passive recipients of knowledge (Lundahl, 2008). Reported benefits of active learning include enhanced critical thinking skills, deep-level understanding, increased problem-solving skills, and greater enthusiasm in the subject matter (Lundahl, 2008). Lundhal (2008) notes that while attention and interest in active learning strategies are relatively recent, several techniques (e.g. discussion, journaling, writing exercises, student projects, role playing, and skill practice) have a long history in pedagogy and social work. Research points to the effectiveness of active learning strategies in social work research education (Barraket, 2005; Johnson, 2010, Tetloff, Hitchock, Battista, \& Lowry, 2014).

Participatory action research (PAR), a method of "collaborative research that involves increased understanding of an issue of concern and efforts aimed at improving social conditions through individual and group action" (Palibroda, Krieg, Murdock, \& Havelock, 2009, p. 6) has been touted as a useful pedagogical strategy (Tynan, Stewart, Adlington, Littledyke, \& Swinsburg, 2008). Photovoice is a PAR strategy developed in response to the need for a public health tool for working with communities to ground emerging issues in the communities' own definitions of their concerns (Wang \& Burris, 1997). With the underpinnings of Freirian (1973) principles of critical consciousness and feminist theory (Weiler, 1988), Photovoice is a form of documentary photography where the emphasis is on "the central role of people themselves in critically reflecting on, discussing, and defining the 
situations of their everyday lives" (Peabody, 2013, p. 254). Photovoice empowers community members to engage actively and critically, using the images they have taken as a means of expression and sharing of their expertise (Wang \& Burris, 1997). It is an investigative tool that: assists people in critically reflecting on everyday social and political realities of their lives; enriches participants' understanding of their communities and the issues pertinent to them; and gives people a voice from which to educate others on their issues (Wang, 1999). It is both a creative and empowering approach that can serve to elicit advocacy and social change, as photographs are taken and stories are told in a compelling "intermingling of images and words" (Palibroda et al., 2009, p. 8). As Peabody (2013) points out, "Photovoice clearly has the potential to be a powerful tool in a social worker's practice repertoire" (p. 255). Dumbrill (2008) and Molloy (2007) make a strong case for the use of Photovoice in social work and by social justice workers, suggesting that Photovoice, or elements thereof, could be a useful addition to the social work educator's toolbox.

Limited reports of the use of Photovoice in teaching and in social work exist. Notable exceptions include Johnson's (2010) use of participatory photography as a means to engage social work students in service-learning and Perry's (2006) employment of a modified version of Photovoice to involve learners actively in the online education process. Finally, Peabody (2013) used Photovoice with MSW students to develop community through sharing photographs and discussing their lived experiences of social injustice, moving from analysis to advocacy.

In our MSW curriculum we offer an introductory, required course, Issues in Social Work Research, which provides an opportunity for students to explore research topics and issues specific to the profession and within a context of social work practice and policy. Using active learning strategies students are tasked with preparing an interactive group presentation as one of the assignments. The present case example is derived from the context of this required assignment. By incorporating the elements of PAR and Photovoice into the class presentation, the project developed into a collaborative experiential process involving the entire class, successfully engaging students in learning about the relevance and effectiveness of participatory research methods. The project used elements of PAR and Photovoice as a means of engaging students in learning about research methods and to answer a question of relevance to student learners. This article describes the processes and outcomes of this teaching strategy.

\section{METHODS}

The participants were 26 students enrolled in the MSW program who were taking an introductory research course as part of the foundation year of a two-year program taught by the lead author. Four students began the project as part of their group assignment.

Students were asked to use Photovoice to reflect upon the question, "What does balance look like for you in the MSW program?" On two separate occasions, the student group members invited students by e-mail, to submit a photograph along with a caption in response to the question. Participation was optional, anonymity of the submissions was maintained unless waived by the individual, and there was no limit placed on the number of submissions an individual student could provide.

Twenty students submitted a total of 32 photographs with captions, which comprised the final sample size for evaluation. During a regular class session, students were provided with a brief tutorial regarding data analytic techniques by the course instructor and copies of the anonymized data set in the form of pictures and accompanying captions. Adopting a pragmatic approach to data analysis (Patton, 2002), in small groups of two or three, students completed line-by-line coding to identify themes and patterns in the data (Wang \& Burris, 1997). Students then selected relevant images and captions as illustrative of the themes and patterns that they had identified. Each small group presented one or two themes to the entire class and a large group discussion ensued to develop a preliminary interpretation of the research question and to provide feedback on the research process. Subsequently, students expressed interest in proceeding with the analysis and report writing, which was carried out by two students in the context of a research practicum, supervised by the course instructor.

A second stage of the analytic process involved a focused review of the data, expanding upon, reevaluating and re-interpreting the preliminary findings. From this, clusters of data were identified which comprised 
themes and sub-themes. Once these were finalized they were provided to the class for further comment and revision as a means of ensuring rigor (Cohen \& Crabtree, 2008).

\section{RESULTS}

Students portrayed diverse definitions of 'balance' and the means through which it was achieved. Balance was described in a state of fluidity existing along a continuum from balanced to unbalanced and was contextualized to the specific point in time in students' academic journey and as existing in a state of fluidity. Balance was comprised of four major themes: Connection, Nurturance, Keeping Perspective, and Disengagement, each of which is described with illustrative quotes drawn from the captions and images.

\section{Connection}

Several students described feeling a Connection to self, others, the natural world, the social work profession, and the academic setting. Frequently, the relational aspect and attunement to self and external factors were experienced as a grounding force, particularly when student demands were high. Referred to as "mindfulness", by some participants, connection implied a bond between physical, mental, emotional, social and spiritual realms. One student commented that balance was achieved by taking the time to enjoy the outdoors and being, "connected to my breath and tuning out all of the noise that resounds each day"; this, the participant explained, served as a "stepping away" for pause and ponder. Another student depicted her sense of self in relation to her multiple roles as "Student. Mother. Artist. Runner. Daughter. Woman.", through an image of her son alongside an art creation, showing the importance of these two aspects of her life. She added that these two spheres of her life were most affected when she was feeling overwhelmed with schoolwork. A third student elaborated on the significance of having a strong network of friendships which formed part of a support system that helped her stay "emotionally well" while yet another student captured the sense of attachment through a photograph of distant mountain peaks (Figure 1).

In Alberta for school, I am farther from home, yet closer to the mountains. And in the mountains, I feel more connected with everything; so insignificant, yet safe at home. In order to experience this feeling, I had to take a step back from the studies and briefly run away with my boyfriend. I found myself seeing that Masters of Social Work program is my mountain. Its intimidation delayed me, yet now its beauty moves me towards it. I must balance the enjoyment with the climb, and soon I will reach the top.

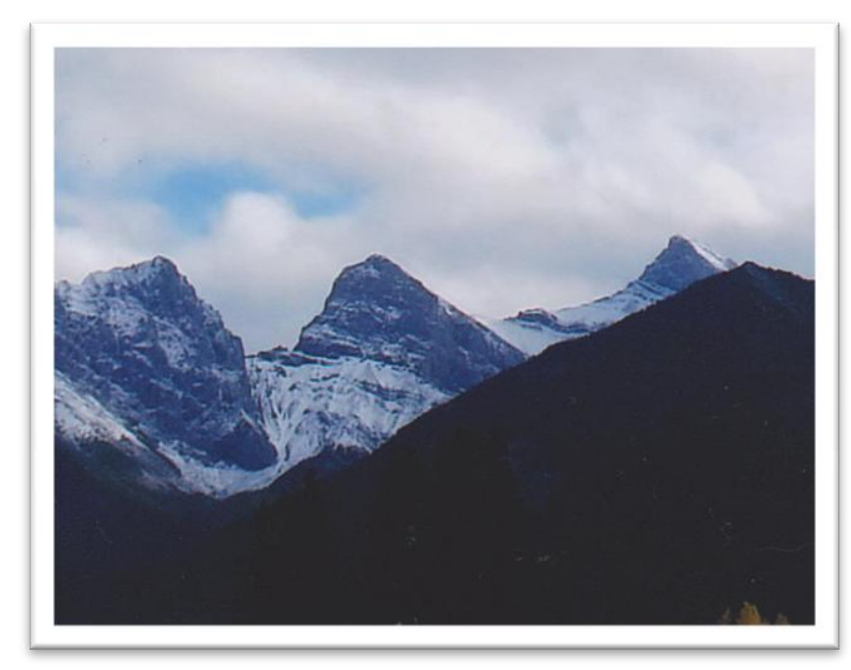

Figure 1: Mountain Peaks 


\section{Nurturance}

The second major theme, Nurturance, involved achieving balance through engaging in self-care activities including: sleep; rest; healthy diet; physical exercise; and cultivating interests outside of academia. The ability to nourish one's mind, body and soul was associated with good health, while the absence of such was seen to be stressful and detrimental. One student stated:

Balance for me means having enough time to make healthy meals. Often when I get stressed and busy I grab snacks on the go, and my eating is not as balanced as it should be. Eating healthy meals makes me feel better and more balanced as my body is getting what it needs to manage my busy schedule.

A common descriptor within the nurturance theme is "having time", specifically there being "enough" time to "be able" to engage in nurturing activities. One student suggested, that "having time to relax and recharge is vital" and could be achieved by spending time reading "something other than a textbook". Another participant used an image of cook books (Figure 2) and elaborated:

Taking time for me. Balance means that I am still able to do the things I enjoy such as cooking, or reading a book for pleasure (rather than a textbook). This shelf represents balance and relaxation. And heart's ease balances their lives.

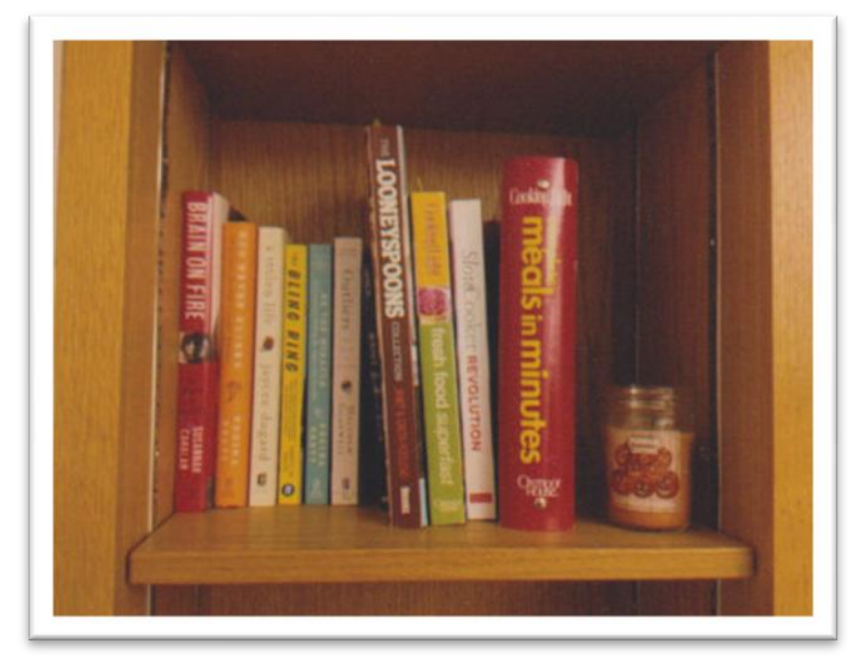

Figure 2: Cookbooks

\section{Keeping Perspective}

Many students identified that Keeping Perspective was useful in coping with stressors associated with school and competing demands. Participants suggested that keeping perspective involved prioritizing tasks, being adaptable, maintaining a sense of humor, and focusing on achieving current and future goals. The ability to make one's own choices was a common thread throughout. One student likened the MSW program experience to that of solo canoeing down a river, stating that, "sometimes you have to lean to one side to maintain balance". Similarly another student described "dancing through the chaos and... happy to be here". An image submitted by one student was of a school textbook, a ring, and a paycheck lying next to each other, with the caption "Sometimes I feel like I can only choose one". Along these lines, another student provided a photograph of a newborn with the accompanying statement, "It's about following my heart as a mother and keeping the vision of finishing my education", to signify her choice to add to her family in the midst of her school pursuits. Another photo captured a student enjoying "the simple things in life" after becoming "engrossed in and slightly overwhelmed" with school responsibilities - this student has her feet up on the couch, with her dog alongside her doing the same with its paw. "Taking time to find humor and levity amid an often hectic and stressful time," was credited by one student as a 
strategy to achieve balance. Similarly a student compared the MSW program to a rainstorm with the appearance of a rainbow at the end (Figure 3), noting, "We should work hard, study hard, and learn, but there should be time to stop and see the rainbow. There should be rainbow moments during the semester, not just a constant downpour of required activities".

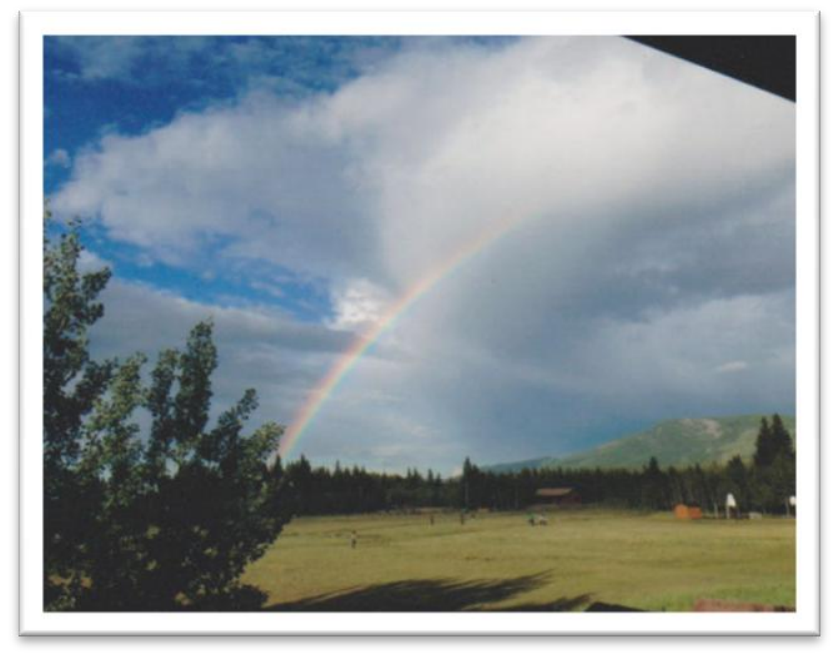

Figure 3: Rainbow

Acceptance and Reconciliation were identified as sub-themes of nurturance. Participants defined acceptance as coming to terms with the stress and challenge inherent to graduate level education while reconciliation was described as becoming resigned while striving to find harmony in "the moment". One student used an image of students resting on the grass on a sunny day, explaining that it was a restorative practice for many students:

During lunch time people rest on the grass, perfectly calm and peaceful. They usually have just one hour between super intense classes of their super intense programs, but they use this hour in a best possible way: just relaxing under warm sun. When I see them I think at the moment they are not disturbed by their workloads, assignments, future careers, and present household chores. This one hour of complete freedom.

The reciprocal relationship between acceptance and reconciliation was illustrated by one student who provided an image of a clean counter with a cup of coffee stating, "This photo represents balance to me. Everything is calm. The counter is empty and clean. The coffee is fresh. It represents all my tasks having been taken care of. (Haha, not the reality at ALL!)".

\section{Disengagement}

Some students described encountering challenges with finding balance while in the MSW program articulating a sense of despair, stress, defeat, and dispassion. Students depicted a struggle in trying to attain balance. For example, one student used the image of onions on a chopping block, noting, "It's difficult to keep the balance. Sometimes things are just too dry and they make you cry". Another student acknowledged having no balance. "I can't balance anything anymore" as illustrated by a cartoon image of a man and his black dog hiding under a desk piled high with work yet uncompleted. An alternative interpretation of this image was offered, suggesting that the image of a black dog is a common metaphor for depression (Nemeroff, 2001). However the nature of this disengagement was ambiguous and could not be clarified given the anonymous nature of the images. A third student used the image of a total blackness, "There exists no balance. It is just a dark abyss of paper writing and stress". One student used the word, "Meh", to express ambivalence or lack of interest concerning the process of becoming disengaged (Figure 4), "I tried to balance caring about everything... and now I can't care about anything. I wish something, anything, would re-spark my passion". 


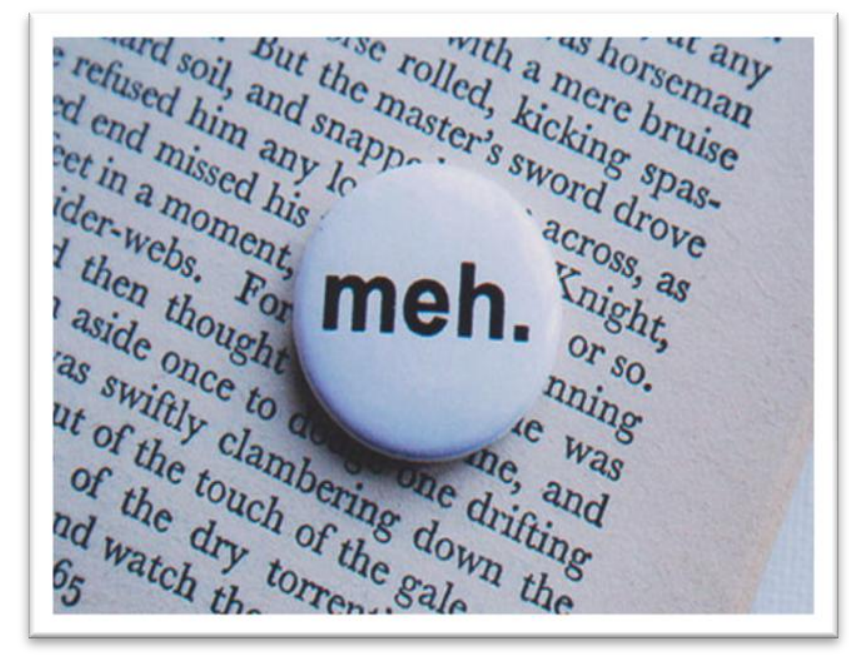

Figure 4: Meh

\section{DISCUSSION}

A PAR framework was used to engage students in a Photovoice activity to learn about social work research. The techniques facilitated students' active involvement in research including: problem formulation; design; data collection; and qualitative data analysis and interpretation. This process provided an opportunity for students to reflect critically upon a question of interest and relevance to their own lives.

Although this teaching strategy was not formally assessed, preliminary impressions show that students benefited from the process of participating in the Photovoice activity. In the context of a class discussion, students provided positive feedback regarding the Photovoice research technique and the active engagement in the research process. Comments reflected an appreciation for the Photovoice method as a participatory research tool and the opportunity to experience it within the classroom setting. One student remarked on the sense of community that was created in the classroom through the sharing of lived experience, stating that it was the first time she felt like she had gotten to know her cohort and that it was comforting knowing that she "wasn't the only one who became stressed out with school". Another comment alluded to the use of Photovoice as a classroom activity allowed for some "fun" through creative expression while providing learning about research methods and actual issues surrounding student life balance. It was also noted by some students that Photovoice provided the means for thoughts to be expressed through imagery, as chosen by the participant. Acknowledging the value of class involvement, one student expressed his intent to incorporate Photovoice and other PAR methods into his future social work practice with communities.

Through engaging in participatory photography, students were able to answer the research question by articulating their own concerns and ideas. The analysis revealed that balance existed along a continuum from balance to unbalance and that various factors either contributed to students achieving balance, or becoming ambivalent and descending into a state of unbalance. These findings are consistent with studies identifying that adult learners, particularly those with multiple roles outside of school, can be challenged with adjustment, stress levels, and coping strategies (Moreno, 2014; Schneider, 2008; Ting, Morris, McFeaters, \& Eustice, 2006; Wilkes, 2008).

Engaging in the Photovoice activity highlighted students' shared experience, which contributes to a sense of community and aids in engagement in learning (Lichty, 2013; Perry, 2006). Further, Lichty (2013) noted that as a pedagogical tool Photovoice "brings course content to life and it is a meaningful way to engage students in their communities" (p. 96). Barrket (2005) suggests that utilizing approaches that encourage active and experiential engagement with the subject matter promotes student enjoyment and learning. Student engagement and learning is enhanced when the subject material is relevant to students; when it captures their interest and capitalizes on their lived experience (Harder, 2010; Holley, Risley-Curtiss, Stott, Jackson, \& Nelson, 2007; Jacobson \& Goheen, 2006). 
Carawan et al. (2011) refer to this type of engagement as "situating cognition in the research process [and] in a personal text" (p. 394). The Photovoice activity, in this case, fostered participation in 'real' research leading students to understand and value both the participatory research methods and the results of the investigation, a finding that is consistent with the literature on active learning strategies (Holley et al 2007; Tetloff, Hitchcock, Battista, \& Lowry, 2014).

Although alternate research methods, such as PAR, have shown promise in teaching research (Maschi, Probst, \& Bradley, 2009), further studies are needed to explore the significant factors that impact students' learning. While the feedback from students regarding the project was predominantly positive, there were a number of limitations of this teaching model. Given that his project was initially developed as part of a group presentation the initial research question was developed by a small group of students and not the entire class as would be expected according to participatory principles. There were limited opportunities for students to continue work on this project within class time throughout the course and the final data analysis was completed by a small number of class members. While the anonymity of the data collection protected students from any potential negative consequences of their submitted images, it was not then possible to approach individual participants directly for clarification as to the meaning of a given submission. Importantly, there was a lack of formal assessment of student engagement and learning. Future research is necessary to determine the effectiveness of this teaching strategy in promoting active learning to teach participatory research techniques.

\section{CONCLUSION}

While more research is required to evaluate the effectiveness of using Photovoice as a tool to contribute to research engagement, we offer this strategy as a promising case example to enhance research familiarity, knowledge and engagement among MSW students. Also within this process, students may have the opportunity to investigate a research question of direct relevance in their lives. Experiential and active learning techniques such as Photovoice may be useful in preparing students to be competent in consuming and producing research. Additionally, this study provides insight into students' perspectives of balance and strategies used to achieve it. The substantial number of students identifying the salience of 'disengagement' suggests the need for further research on the achievement of balance for graduate MSW students.

\section{ACKNOWLEDGMENTS}

We would like to express our thanks to the MSW Fall 2014 Class, Issues in Social Work Research for their enthusiastic engagement in this research and to Margaret Baker, Jamie Hickey, Paul Lapointe and Noelle Lee for their development of this case example to teach participatory research.

\section{AUTHOR INFORMATION}

Christine A. Walsh, PhD, Professor, Faculty of Social Work, University of Calgary, Calgary, Alberta, has a program of participatory action and arts-based research aimed at contributing the social justice and well-being for marginalized populations. She is also interested in developing, implementing and evaluating innovative pedagogical methods. E-mail: $\underline{\text { cwalsh@ucalgary.ca }}$

Patsy J. Casselman, MSW student, Faculty of Social Work, University of Calgary in the international and community development stream. Prior to embarking on her studies, she completed a Bachelor of Child and Youth Care Counseling University of Victoria, B. C. and is a Certified Child Life Specialist. Previously, Patsy worked at Alberta Children's Hospital, providing psychosocial support to children, youth and their families and as a facilitator of a youth advisory council in the health care setting. She is interested in preventative care and the social determinants of health and the effects of inequality on individuals, families and communities and in participatory action research and policy development.

Jamie Hickey, MSW student, Faculty of Social Work, University of Calgary, has research interests primarily in the areas of mental health and professional practice development. Jamie is currently completing her thesis and holds a 
Master's award from Canada Graduate Scholarships (CGS-M) under the Social Sciences and Humanities Research Council of Canada (SSHRC).

Noelle Lee, MSW student, Faculty of Social Work, University of Calgary. Her current academic focus is on international and community development and Noelle works as a co-therapist in long-term group psychotherapy. Previously, Noelle completed her Bachelor of Arts in Family Studies from the University of British Columbia, Vancouver, B.C., Canada, and worked in community development in Vancouver, Ecuador, and Mexico.

Harold Pliszka, MSW Student, Faculty of Social Work, University of Calgary, holds a Bachelor of Human Ecology in Foods and Nutrition from the University of Manitoba, Winnipeg, Manitoba. Harold is president and cofounder of both Helping Youth Through Educational Scholarships and Iron Lava Corp and serves on the Board of Directors for Calgary Outlink Centre for Gender and Sexual Diversity.

\section{REFERENCES}

Barraket, J. (2005). Teaching research method using a student-centered approach? Critical reflections on practice. Journal of University Teaching and Learning Practice, 2, 65-74.

Cameron, P.J. \& Este, D.C. (2008). Engaging students in social work research education. Social Work Education, 27(4), 390-406.

Canadian Association of Schools of Social Work. (2004). CASSW Standards for accreditation, May 4. Ottawa, Ontario. Retrieved from http://www.mun.ca/cassw-ar/accstans/

Carawan, L.W., Knight, S., Wittman, P., Pokorny, M., \& Velde, B.P. (2011). On becoming a qualitative researcher: A view through the lens of transformative learning. Journal of Teaching in Social Work, 31, 387-399.

Cohen, D. J. \& Crabtree, B. F. (2008). Evaluative criteria for qualitative research in health care: Controversies and recommendations. Annals of Family Medicine, 6(4), 331-339. doi: 10.1370/afm.818

Dumbrill, G.C. (2008). Your policies, our children: Messages from refugee parents to child welfare workers and policymakers. Child Welfare, 88(3), 145-168.

Epstein, I. (1987). Pedagogy of the perturbed: Teaching research to the reluctants. Journal of Teaching in Social Work, 1(1), 71-89.

Epstein, I. (2011). Reconciling evidence-based practice, evidence-informed practice, and practice-based research: The role of clinical data-mining. Social Work, 56(3), 284-288.

Gambrill, E. (2006). Social work practice: A critical thinker's guide (2 ${ }^{\text {nd }}$ ed.). New York: Oxford Press.

Green, R.G., Bretzin, A., Leininger, C., \& Stauffer, R. (2001). Research learning attributes of graduate students in social work, psychology, and business. Journal of Social Work Education, 37(2), 333-341.

Harder, J. (2010). Overcoming MSW students' reluctance to engage in research. Journal of Teaching in Social Work, 30. 195-209.

Hewson, J., Walsh, C. A., \& Bradshaw, C. (2010). Enhancing social work research education through research field placements. Contemporary Issues in Education Research, 3(9), 7-15.

Holley, L.C., Risley-Curtiss, C., Stott, T., Jackson, D.R., \& Nelson, R. (2007). “It's not scary": Empowering women students to become researchers. Affilia: Journal of Women and Social Work, 22(1), 99-115.

Howard, M.O, Himle, J., Jenson, J.M., \& Vaughn, M.G. (2009). Revisioning social work clinical education: Recent developments in relation to evidence-based practice. Journal of Evidence-based Social Work, 6, 256-273.

Jacobson, M. \& Goheen, A. (2006). Engaging students in research: A participatory BSW program evaluation. Journal of Baccalaureate Social Work, 12(1), 87-104.

Jenson, J.M. (2007). Evidence-based practice and the reform of social work education: A response to Gambrill and Howard and Allan-Meares. Research on Social Work Practice, 17(5), 569-573.

Johnson, M. (2010). Teaching macro practice through service learning using participatory photography. Journal of Community Practice, 18, 297-314.

Lazar, A. (1991). Faculty, practitioner, and student attitudes toward research. Journal of Social Work Education, 27(1), 35-40.

Lundahl, B.W. (2008). Teaching research methodology through active learning. Journal of Teaching in Social Work, 28(1/2), 273-288.

Lichty, L.F. (2013). Photovoice as a pedagogical tool in the community psychology classroom. Journal of Prevention \& Intervention in the Community, 41(2), 89-96. 
Lyons, K. (2000). The place of research in social work education. British Journal of Social Work, 30(4), 433-447. doi: $10.1093 / \mathrm{bjsw} / 30.4 .433$

MacIntrye, G. \& Paul, S. (2013). Teaching research in social work: Capacity and challenge British Journal of Social Work, 43(4), 685-702. doi: 10.1093/bjsw/bcs010

Maschi, T., Probst, B. \& Bradley, C. (2009). Mapping social work students' perceptions of the research process: A qualitative follow-up study. Journal of Baccalaureate Social Work, 14(2), 63-78.

Maschi, T., Bradley, C., Youdin, R., Killian, M.L., Cleaveland, C., \& Barbera, R.A. (2007). Social work students and the research process: Exploring the thinking, feeling, and doing of research. Journal of Baccalaureate Social Work, 13(1), 1-12.

Maynard, B.R. (2007). To EBP or not to EBP?: Social work's dilemma with Evidence Based Practice. PRAXIS, 7, 515.

Molloy, J.K. (2007). Photovoice as a tool for social justice workers. Journal of Progressive Human Services, 18(2), $39-55$.

Moreno, P. (2014). Stress in Master of Social Work students. [Master's thesis]. Retrieved from Stanislaus Scholar Works. http://scholarworks.csustan.edu/handle/011235813/732 (2014-05-21T19:07:33Z)

Nemeroff, C. B. (2001). Progress in the battle with the black dog: Advances in the treatment of depression. American Journal of Psychiatry, 158(10), 1555-1557.

Nevo, I. \& Slonim-Nevo, V. (2011). The myth of evidence-based practice: Towards evidence-informed practice.

British Journal of Social Work, 41(6), 1176-1197. doi: 10.1093/bjsw/bcq149

Palibroda, B., Krieg, B., Murdock, L, \& Havelock, J. (2009). A practical guide to Photovoice: Sharing pictures, telling stories and changing communities. Winnipeg, MB: The Prairie Women's Health Centre of Excellence.

Patton, M.Q. (2002). Qualitative research \& evaluation methods (3rd ed.). Thousand Oaks: Sage Publications.

Peabody, C.G. (2013). Using Photovoice as a tool to engage social work students in social justice. Journal of Teaching in Social Work, 33(3), 251-265.

Perry, B. (2006). Using photographic images as an interactive online teaching strategy. Internet and Higher Education, 9(3), 229-240.

Petch, A. (2010). Swings and roundabouts: From evaluation to evidence-informed practice in social services. Revista de Asistenta Sociala, 9(4), 29-39.

Secret, M., Ford, J. \& Rompbf, E.L. (2003). Undergraduate research courses: A closer look reveals complex social work student attitudes. Journal of Social Work Education, 39(3), 411-422.

Schneider, D. (2008). Reflections from a student of mothering. Smith College Studies in Social Work, 78(4), 469474.

Tetloff, M., Hitchock, L., Battista, A. \& Lowry, D. (2014). Multimodal composition and social justice: Videos as a tool of advocacy in social work pedagogy. Journal of Technology in Human Services, 32(1-2), 22-38.

Thyer, B.A. (2008). The quest for evidence-based practice?: We are all positivists! Research on Social Work Practice, 18(4), 339-345.

Ting, L., Morris, K.J., McFeaters, S.J. \& Eustice, L. (2006). Multiple roles, stressors, and needs among baccalaureate social work students: An exploratory study. Journal of Baccalaureate Social Work, 12(1), 39-55.

Tynan, B., Stewart, C., Adlington, R., Littledyke, M. \& Swinsburg, S. (2008). Participatory action research for professional development: Changing our approach to distance learning. In Hello! Where are you in the landscape of educational technology? Proceedings ascilite Melbourne 2008. Retrieved from http://www.ascilite.org.au/conferences/melbourne08/procs/tynan.pdf

Wang, C.C. (1999). Photovoice: A participatory action research strategy applied to women's health. Journal of Women's Health, 8(2), 185-192.

Wang, C.C. \& Burris, M.A. (1997). Photovoice: Concept, methodology, and use for participatory needs assessment. Health Education and Behavior, 24(3), 369-387.

Walsh, C.A. \& Hewson, J. (2012). A comparison of two methods of teaching research to Master of Social Work students. International Journal of Higher Education, 1(1), 14-21.

Weiler, K. (1988). Women teaching for change: Gender, class, and power. South Hadley, MA: Bergin and Garvey.

Wilkes, S. (2008). Resilience amid academic stress: The moderating impact of social support among social work students. Advances in Social Work, 9(2), 106-125. 